\title{
Efeito da adubação silicatada no cultivo de tomateiro sob estresse salino
}

\author{
Ana Janaína Oliveira Rodrigues ${ }^{1}$, Luma Rayane de Lima Nunes ${ }^{2 *}$, Aline Mara Chaves Nunes ${ }^{1}$, \\ Keline Sousa Albuquerque Uchôa ${ }^{1}$
}

\begin{abstract}
RESUMO: O referido experimento foi desenvolvido com o objetivo de avaliar os efeitos de diferentes dosagens de silício via aplicação foliar em plantas de híbridos de Tomate irrigadas com água salina, em condições de cultivo protegido. Utilizou-se o delineamento experimental inteiramente casualizado, com uma testemunha e cinco concentrações de silicato de potássio $\left(\mathrm{K}_{2} \mathrm{SiO}_{3}\right), 0 ; 25 ; 50 ; 75$ e $100 \mathrm{~mL} . \mathrm{L}^{-1}$ de $\mathrm{K}_{2} \mathrm{SiO}_{3}$ e 10 repetições cada. As avaliações ocorreram aos 20, 45, 75 e 90 DAT para: alturas de plantas; diâmetro do caule; número de folhas e porcentagem de clorofila e aos 27, 47, 79 e 87 DAT: número de flores e número de cachos. Também foram avaliados comprimento, peso fresco e seco do sistema radicular, número total de frutos por planta, peso total de frutos, diâmetros longitudinal e vertical dos frutos. Os resultados obtidos foram submetidos à análise de variância $(\mathrm{F} \leq 0,05)$, e as médias submetidas ao teste de Tukey $(\mathrm{P} \leq 0,05)$ e análise de regressão polinomial. A adubação a base de silício possibilita amenizar o efeito do estresse salino na cultura do tomate. As variáveis altura da planta e peso fresco das raízes, apresentaram melhores resultados quando aplicada a dosagem de $25 \mathrm{~mL}$. $\mathrm{L}^{-1}$ de $\mathrm{K}_{2} \mathrm{SiO}_{3}$. Enquanto para número de folhas e de flores a concentração de $75 \mathrm{~mL} . \mathrm{L}^{-1}$ favoreceu o aumento das médias.
\end{abstract}

Palavras-chave: cultivo protegido, estresse salino, Lycopersicum esculentum, silício.

\section{Effect of silica fertilization on tomato cultivation under saline stress}

\begin{abstract}
The objective of this experiment was to evaluate the effects of different dosages of silicon by foliar application in plants of tomato hybrids irrigated with saline water under protected culture conditions. The experimental design was completely randomized, with one control and five concentrations of potassium silicate $\left(\mathrm{K}_{2} \mathrm{SiO}_{3}\right), 0 ; 25 ; 50$; 75 and $100 \mathrm{~mL} \cdot \mathrm{L}^{-1}$ of $\mathrm{K}_{2} \mathrm{SiO}_{3}$ and 10 replicates each. The evaluations occurred at 20, 45, 75 and 90 DAT for: plant heights; stem diameter; number of leaves and percentage of chlorophyll and at 27, 47, 79 and 87 DAT: number of flowers and number of bunches. The length, fresh and dry weight of the root system, total number of fruits per plant, total fruit weight, longitudinal and vertical diameter of fruits were evaluated. The results were submitted to analysis of variance $(\mathrm{F} \leq 0.05)$, and the means submitted to the Tukey test $(\mathrm{P} \leq 0.05)$ and polynomial regression analysis. Silicon fertilization makes it possible to reduce the effect of saline stress on the tomato crop. The plant height and fresh root weight variables presented better results when the $25 \mathrm{~mL} \cdot \mathrm{L}^{-1} \mathrm{~K}_{2} \mathrm{SiO}_{3}$ dosage was applied. As for the number of leaves and flowers, the concentration of $75 \mathrm{~mL} . \mathrm{L}^{-1}$ favored an increase in averages .
\end{abstract}

Keywords: protected cultivation, saline stress, Lycopersicum esculentum, silicon.

\section{INTRODUÇÃO}

A cultura do tomateiro apresenta grande relevância no Brasil. Entre os estados com maior área cultivada do fruto estão São Paulo, Minas Gerais, Goiás e Bahia, com estimativa de produção de 54.714 hectares e colheita prevista em 3.544 .593 toneladas. O nordeste brasileiro apresenta ótimas condições para seu cultivo, com destaque para os Estados da Bahia, Pernambuco e Ceará, responsáveis, por uma área plantada de 11.487 ha, sendo a mais importante olerícola cultivada, com mais de 495.675 mil toneladas produzidas. Além disso, é uma das hortaliças mais consumidas no mundo, tanto in natura, como processada, nas formas de suco, molho, pasta, desidratada, dentre outros (TREICHEL et al., 2016).

A qualidade da água utilizada para irrigação é fator primordial para que as plantas possam expressar seu máximo desenvolvimento e potencial produtivo (Guedes et al., 2015). Neste contexto a utilização de água de baixa qualidade para a irrigação torna-se um fator limitante para a produção vegetal, uma vez que a salinidade inibe o crescimento das plantas, em função dos efeitos

\footnotetext{
Recebido em 04/01/2018; Aceito para publicação em 06/06/2018

${ }^{1}$ Instituto Federal do Ceará

${ }^{2}$ Universidade Federal do Ceará

*E-mail: lumanunes20@ hotmail.com
} 
osmóticos, restringindo a sua disponibilidade e de nutrientes; por toxicidade com acúmulo de íons específicos, principalmente $\mathrm{Na}^{+}$e $\mathrm{Cl}^{-}$, ou por distúrbios na nutrição das plantas, refletindo diretamente no metabolismo e crescimento (FREIRE et al., 2010; TUNA et al, 2008).

Apesar do Si não ser considerado como um elemento essencial ao crescimento das plantas tem apresentado diversos efeitos benéficos em várias espécies, dentre eles: manutenção da taxa fotossintética, aumento da condutância estomática da planta, maior resistência mecânica das células e às doenças e pragas; diminuição do efeito tóxico de $\mathrm{Mn}, \mathrm{Fe}$ e outros metais pesados; aumento da absorção e metabolismo de elementos, tais como fósforo. Além de ter sido associado ao aumento da capacidade de defesa antioxidante diante deficiência hídrica (GONG et al., 2005; HATTORI et al., 2005).

É absorvido pela planta na forma de ácido monossilícico $\left(\mathrm{H}_{4} \mathrm{SiO}_{4}\right)$ juntamente com a água (fluxo de massa) e se acumula principalmente nas áreas de máxima transpiração (tricomas, espinhos, etc.), como ácido silícico polimerizado (sílica amorfa) (Ma, 2004). Em geral, são consideradas plantas acumuladoras de $\mathrm{Si}$, aquelas que possuem teor foliar acima de $1 \%$, e não acumuladoras plantas com teor de silício inferior a 0,5\% (MA; MIYAKE; TAKAHASHI, 2001).

Estudos vem demonstrando que a utilização do silício pode ser utilizada como uma alternativa para minimizar o efeito negativo dos sais nas culturas (Lima et al., 2011). Então, diante desse fato, objetivou-se avaliar o efeito de diferentes dosagens de silicato de potássio $\left(\mathrm{K}_{2} \mathrm{SiO}_{3}\right)$ via aplicação foliar em plantas do híbrido de tomate dominador (Solanum lycopersicum L.), submetidas a estresse por adição de cloreto de sódio $(\mathrm{NaCl})$ na água de irrigação, em condições de cultivo protegido na Chapada do Apodi.

\section{MATERIAL E MÉTODOS}

O experimento foi conduzido, entre os meses de dezembro/2016 a abril/2017, em ambiente protegido situado na área experimental da Unidade de Ensino Pesquisa e Extensão (UEPE) do IFCE - campus Limoeiro do Norte, localizado na Chapada do Apodi, coordenadas geográficas de $05^{\circ} 10^{\prime} 57^{\prime \prime} \mathrm{S}$ e $38^{\circ} 00^{\prime} 46^{\prime \prime} \mathrm{W}$, a uma altitude de $146 \mathrm{~m}$.

As mudas foram produzidas em bandejas plásticas com 200 células preenchidas com substrato Tropstrato ${ }^{\circledR}$ sendo semeada uma semente em cada célula. Durante a fase de desenvolvimento das plântulas foram realizadas aplicação dos fertilizantes: Raizal ${ }^{\circledR}$ via solo e foliar, nas dosagens 7,5 g. $L^{-1}$ e 3 g. $L^{-1}$, respectivamente, a fim de estimular o desenvolvimento radicular das plântulas; e MKP ${ }^{\circledR}$ na dosagem de 3 g. $\mathrm{L}^{-1}$ aplicado via solo.

O transplante ocorreu aos 30 dias após a semeadura (DAS), em vasos de plástico com oito litros de capacidade, preenchidos com substrato formado a partir da mistura de casca de arroz carbonizada e composto orgânico (1:1). Foram selecionadas as plântulas mais vigorosas, com 2 a 3 folhas completas e em bom estado fitossanitário. Cada vaso continha uma muda e após 20 dias do transplantio, período para pré-estabelecimento da cultura, deu-se início a diferenciação dos tratamentos.

A necessidade hídrica exigida pela cultura foi calculada pelo método do tanque Classe A, o qual foi instalado no interior da estufa. $\mathrm{O}$ manejo diário da irrigação se deu pela leitura do nível da água no tanque evaporímetro realizada sempre pela manhã, em intervalos de 24 horas. A água empregada na irrigação, exceto para o tratamento testemunha (sem aplicação de silício e sem irrigação com água salina) tive sua condutividade elétrica ajustada para 2,5 $\mathrm{dS} . \mathrm{m}^{-1}$, a partir da adição de cloreto de sódio à água, sendo considerada com restrição de uso moderado na agricultura de acordo com AYERS e WESTCOT (1999).

O delineamento experimental adotado foi o inteiramente casualizado, com seis tratamentos e 10 repetições. Foram testadas cinco concentrações do produto comercial à base de silicato de potássio, Silica ${ }^{\circledR},\left(0 ; 25 ; 50 ; 75\right.$ e $100 \mathrm{~mL} . \mathrm{L}^{-1}$ de $\left.\mathrm{K}_{2} \mathrm{SiO}_{3}\right)$ pulverizado sobre as folhas de plantas irrigadas com água salina aos 20,50 e 80 dias após o transplantio (DAT).

As avaliações dos parâmetros biométricos das plantas ocorreram aos 20, 45, 75 e 90 DAT para: alturas de plantas (AP) - determinada em centímetros com o auxílio do metro dobrável graduado, correspondendo à distância entre a base e o ápice; diâmetro do caule (DC) - determinado em centímetros com o auxilio de um paquímetro analógico, com os valores obtidos da região basal da planta a um centímetro da superfície do solo; número de folhas $(\mathrm{NF})$ - contadas somente as verdes ou com pequenos danos; a porcentagem de clorofila (PC) nas folhas localizadas na parte mediana da planta com o auxílio do equipamento ClorofiLOG®, modelo CFL 1030.

As demais variáveis foram avaliadas ao final do experimento após 103 DAT, dentre elas: comprimento da raiz (CR) - em centímetros, determinado por meio da medição da maior ramificação observada fazendo-se uso de metro dobrável; peso fresco das raízes (PFR) - em gramas, obtido pela pesagem das raízes em balança de precisão com três casas decimais, imediatamente após a coleta das mesmas; peso seco das raízes 
(PSR) - as raízes foram acondicionadas em sacos de papel e colocados em estufa a uma temperatura de $65^{\circ} \mathrm{C}$ por 72 horas.

Em relação aos parâmetros produtivos, foram avaliados: número de flores (NFL) e número de cachos (NC) - sendo considerados apenas os que continham flores abertas ou em formação, com as avaliações realizadas aos 27, 47, 79 e 87 DAT; e número total de frutos por planta (NFP), peso total de frutos (PTF) - pesados em balança semi-analítica; diâmetros longitudinal (DLF) e vertical (DVF) dos frutos, ambos utilizando paquímetro analógico. As avalições de NFP, PTF, DLF e DVF foram realizadas após cada colheita, ocorridas aos 89,94 , 100 e 103 DAT.

Os parâmetros avaliados foram submetidos à análise de variância $(\mathrm{F} \leq 0,05)$, e as médias comparadas pelo teste de Tukey $(\mathrm{p} \leq 0,05)$ utilizando o programa estatístico Assistat, versão 7.7.

\section{RESULTADOS E DISCUSSÃO}

O estudo da análise de variância para os parâmetros biométricos (Tabela 1) mostrou efeito significativo nas diferentes dosagens de silício para as variáveis: altura das plantas aos 45 DAT, número de folhas aos 45 e 90 DAT, e porcentagem de clorofila aos 20 DAT.

Tabela 1 - Resumo da análise de variância para as variáveis: altura (AP), número de folhas (NF), diâmetro do caule (DC) e porcentagem de clorofila de plantas de tomate aos 20, 45, 75 e 90 dias após o transplantio (DAT), Limoeiro do Norte-CE, 2017.

\begin{tabular}{lllll}
\hline \multirow{2}{*}{ Variáveis } & \multicolumn{4}{c}{ QM } \\
\cline { 2 - 5 } & $20 \mathrm{DAT}$ & $45 \mathrm{DAT}$ & $75 \mathrm{DAT}$ & $70 \mathrm{DAT}$ \\
\hline $\mathrm{AP}$ & $25,19 \mathrm{~ns}$ & $978,79 * *$ & $771,27 \mathrm{~ns}$ & $761,09 \mathrm{~ns}$ \\
$\mathrm{NF}$ & $1,86 \mathrm{~ns}$ & $13,36 *$ & $16,50 \mathrm{~ns}$ & $50,71 * *$ \\
$\mathrm{DC}$ & $1,38 \mathrm{~ns}$ & $1,45 \mathrm{~ns}$ & $1,28 \mathrm{~ns}$ & $0,57 \mathrm{~ns}$ \\
$\mathrm{PC}$ & $70,79 *$ & $127,51 \mathrm{~ns}$ & $113,63 \mathrm{~ns}$ & $226,65 \mathrm{~ns}$ \\
\hline
\end{tabular}

(ns) - não significativo; (*) significativo ao nível de 5\% de probabilidade (p<0,05); (**) significativo ao nível de $1 \%$ de probabilidade $(\mathrm{p}<0,01)$.

O estresse salino causou redução na pressão de turgescência em virtude da diminuição do conteúdo de água, resultando em declínio na expansão da parede celular, menor crescimento e baixa produção de matéria seca. Em se tratando da utilização de silício na minimização dos efeitos do estresse salino, algumas pesquisas já foram desenvolvidas com esse objetivo, Lima et al. (2011), afirmam que a aplicação de silício na solução nutritiva na cultura de milho sob estresse salino, atenuou o efeito negativo causado pelo sal sobre o crescimento das plantas; porém, em um mesmo ensaio realizado com feijão de corda, esses autores não obtiveram resultados semelhantes. Soratto et al. (2011), ao avaliarem a influência do silício sobre a produção de tubérculos de batata, concluíram que a aplicação do silício via foliar promoveu um aumento crescente. Entretanto, Gomes et al. (2009) trabalhando com a mesma espécie, obtiveram resultados opostos ao acima mencionados, afirmando que a adubação silicatada não promoveu diferença no desenvolvimento e produtividade da batata. Pereira Júnior et al. (2010), observaram uma relação proporcional entre doses crescentes de silício aplicados no sulco de semeadura e aumento no número de grãos de soja.

De acordo com os resultados apresentados na tabela 2, foi observado que plantas submetidas à condição de estresse salino e/ou sódico e adubadas via foliar com silicato de potássio aos 45 DAT, apresentaram um comportamento diferenciado entre os tratamentos. Nota-se que, quando se utilizou a dose de $25 \mathrm{~mL} . \mathrm{L}^{-1}$ foram obtidos médias estatisticamente semelhantes ao das plantas não condicionadas ao estresse e não adubadas com $\mathrm{Si}$ (Testemunha). Entretanto, as submetidas ao estresse, mas não adubadas com $\mathrm{Si}\left(0 \mathrm{~mL} \cdot \mathrm{L}^{-1}\right.$ de $\left.\mathrm{K}_{2} \mathrm{SiO}_{3}\right)$ apresentaram altura média inferior às que receberam adubação ( $25 \mathrm{~mL} . \mathrm{L}^{-1} \quad \mathrm{~K}_{2} \mathrm{SiO}_{3}$ ), demonstrando uma tendência de que o uso do silício na fase de desenvolvimento inicial do tomateiro, em pequenas dosagens ajuda a superar os efeitos do estresse.

Tabela 2 - Médias obtidas para a variável altura das plantas de tomate aos 20,45, 75 e 90 dias após o transplantio (DAT), Limoeiro do Norte-CE, 2017.

\begin{tabular}{lllll}
\hline & \multicolumn{3}{c}{ Médias } \\
\cline { 2 - 5 } & $20 \mathrm{DAT}$ & $45 \mathrm{DAT}$ & $75 \mathrm{DAT}$ & $90 \mathrm{DAT}$ \\
\hline Testemunha & $22,59 \mathrm{~A}$ & $82,30 \mathrm{~A}$ & $136,33 \mathrm{~A}$ & $148,75 \mathrm{~A}$ \\
0 & $22,00 \mathrm{~A}$ & $78,22 \mathrm{ABC}$ & $123,44 \mathrm{~A}$ & $127,00 \mathrm{~A}$ \\
25 & $20,15 \mathrm{~A}$ & $79,66 \mathrm{~A}$ & $122,33 \mathrm{~A}$ & $124,11 \mathrm{~A}$ \\
50 & $21,10 \mathrm{~A}$ & $63,90 \mathrm{BCD}$ & $117,62 \mathrm{~A}$ & $122,25 \mathrm{~A}$ \\
75 & $18,45 \mathrm{~A}$ & $62,33 \mathrm{CD}$ & $117,65 \mathrm{~A}$ & $135,28 \mathrm{~A}$ \\
100 & $22,37 \mathrm{~A}$ & $59,67 \mathrm{D}$ & $108,11 \mathrm{~A}$ & $130,14 \mathrm{~A}$ \\
\hline CV $(\%)$ & 18,67 & 17,11 & 26,57 & 23,15 \\
\hline
\end{tabular}

As médias seguidas pela mesma letra dentro da mesma coluna não diferem estatisticamente entre si pelo Teste de Tukey ao nível de 5\% de probabilidade ( $\mathrm{p}<0,05)$.C.V. = coeficiente de variação. 
A adubação silicatada foi significativa apenas aos 45 DAT para altura das plantas e número de folhas. Esses resultados são contrários aos obtidos por Carvalho Júnior et al. (2014), os quais não constataram efeito significativo das dosagens de silício e água salina na altura das plantas de pinhãomanso. Esses autores relataram haver influência apenas na salinidade da água na altura das plantas, aumento na altura à medida que se elevava os níveis de salinidade.

Para o número de folhas (Tabela 3) foi verificado que aos 45 DAT as plantas dos tratamentos salinos e que e receberam adubação foliar à base de silício, na concentração de 0 e $25 \mathrm{~mL} . \mathrm{L}^{-1}$, se assemelharam à testemunha, a qual não estava submetida à irrigação com adição de $\mathrm{NaCl}$.

Tabela 3 - Médias obtidas para variável número de folhas de plantas de tomate aos 20, 45, 75 e 90 dias após o transplantio (DAT), Limoeiro do Norte-CE, 2017.

\begin{tabular}{lllll}
\hline \multirow{2}{*}{ Doses de $\mathbf{K}_{\mathbf{2}} \mathbf{S i O}_{\mathbf{3}}\left(\mathbf{m L} \mathbf{L}^{-\mathbf{1}}\right)$} & \multicolumn{4}{c}{ Médias } \\
\cline { 2 - 5 } & $20 \mathrm{DAT}$ & $45 \mathrm{DAT}$ & $75 \mathrm{DAT}$ & $90 \mathrm{DAT}$ \\
\hline Testemunha & $7,40 \mathrm{~A}$ & $13,10 \mathrm{~A}$ & $15,78 \mathrm{~A}$ & $4,12 \mathrm{~B}$ \\
0 & $7,40 \mathrm{~A}$ & $13,22 \mathrm{~A}$ & $14,00 \mathrm{~A}$ & $7,86 \mathrm{AB}$ \\
25 & $7,20 \mathrm{~A}$ & $13,22 \mathrm{~A}$ & $16,33 \mathrm{~A}$ & $\mathrm{~A}$ \\
50 & $6,80 \mathrm{~A}$ & $11,10 \mathrm{AB}$ & $14,87 \mathrm{~A}$ & $11,29 \mathrm{~A}$ \\
75 & $6,40 \mathrm{~A}$ & $11,56 \mathrm{AB}$ & $15,25 \mathrm{~A}$ & $10,57 \mathrm{~A}$ \\
100 & $7,50 \mathrm{~A}$ & $10,56 \mathrm{~B}$ & $12,56 \mathrm{~A}$ & 42,59 \\
\hline $\mathrm{CV}(\%)$ & 16,77 & 19,00 & 37,41 & $\mathrm{~A}$ \\
\hline
\end{tabular}

As médias seguidas pela mesma letra dentro da mesma coluna não diferem estatisticamente entre si pelo Teste de Tukey ao nível de $5 \%$ de probabilidade ( $\mathrm{p}<0,05)$.

C.V. = coeficiente de variação.

Aos 90 DAT pôde-se perceber que o aumento na concentração de silicato de potássio foi diretamente proporcional ao número de folhas, exceto, para 100 $\mathrm{mL} . \mathrm{L}^{-1}$. Já, dentro do mesmo tratamento, o número de folhas aumentou até os 75 DAT, declinando em seguida. Demonstrando que até esse limite, o binômio salinidade e dosagens de silicato de potássio não são prejudiciais a produção vegetativa do tomateiro. Mas, conforme vai-se avançando o tempo, o sal tende a acumular-se no substrato e as dosagens de $\mathrm{K}_{2} \mathrm{SiO}_{3}$ foram capazes de amenizar os efeitos do estresse salino, conforme pode ser observado ao analisar a média do número de folhas para a dosagem zero. E ao proceder um comparativo entre 90 e 20 DAT, com as médias do primeiro superior a esse.

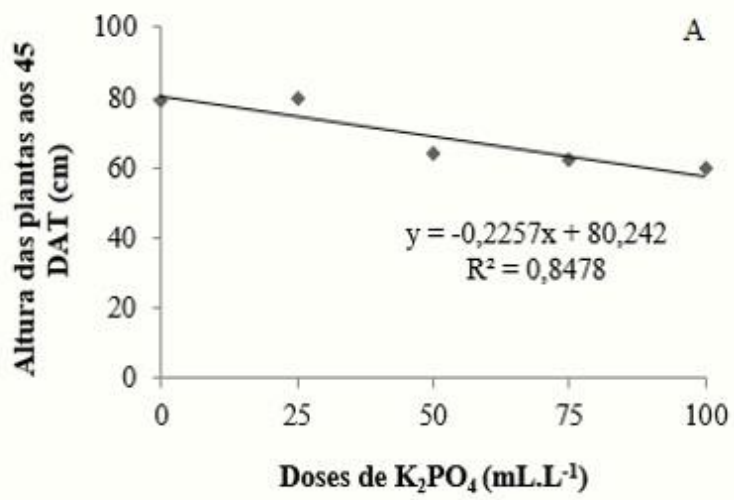

A análise de regressão obtida para as médias da variável altura das plantas e doses de silicato de potássio (Figura 1A) se ajustaram a uma equação de primeiro grau $\left(\mathrm{R}^{2}=0,85\right)$, em que o aumento da dose de Si não promoveu redução no crescimento das plantas de tomateiro sob condição de estresse por sais. Quando se analisa a relação entre doses de $\mathrm{Si}$ e os valores médios obtidos para número de folhas (Figura 1B), obteve-se regressões com comportamento decrescente aos 45 DAT $\left(R^{2}=0,81\right)$ e crescente aos 90 DAT $\left(\mathrm{R}^{2}=0,86\right)$. Essas informações confirmam o efeito benéfico do silício à medida que as plantas tornam-se mais velhas devido à sua possível deposição e polimerização, na forma de sílica, nas folhas, conferindo maior resistência ao estresse.

Figura 2 - Altura de plantas aos 45 DAT (A) e número de folhas aos 45 e aos 90 DAT (B) de tomate em resposta a doses de silicato de potássio aplicadas via foliar. Limoeiro do Norte-CE, 2017. 
Quanto ao percentual de clorofila nas plantas, somente foi observada diferença significativa (Tabela 4) aos 20 DAT, ou seja, antes que fossem diferenciados os tratamentos. Nas avaliações subsequentes (45, 75 e 90 DAT) houve uma equivalência entre as plantas submetidas ao estresse e a testemunha, o que pode significar adaptação da planta sob condições de estresse salino e/ou sódico por ação do silício nas plantas.

Tabela 4 - Médias obtidas para variável porcentagem de clorofila aos 20,45, 75 e 90 dias após o transplantio (DAT), Limoeiro do Norte-CE, 2017.

\begin{tabular}{lllll}
\hline \multirow{2}{*}{ Doses de $\mathbf{K}_{\mathbf{2}} \mathbf{S i O}_{\mathbf{3}}\left(\mathbf{m L} \cdot \mathbf{L}^{-\mathbf{1}}\right)$} & \multicolumn{4}{c}{ Médias } \\
\cline { 2 - 5 } & $20 \mathrm{DAT}$ & $45 \mathrm{DAT}$ & $75 \mathrm{DAT}$ & $90 \mathrm{DAT}$ \\
\hline Testemunha & $45,62 \mathrm{AB}$ & $51,31 \mathrm{~A}$ & $53,68 \mathrm{~A}$ & $46,76 \mathrm{~A}$ \\
0 & $43,03 \mathrm{AB}$ & $43,71 \mathrm{~A}$ & $54,06 \mathrm{~A}$ & $38,86 \mathrm{~A}$ \\
25 & $43,16 \mathrm{AB}$ & $47,98 \mathrm{~A}$ & $46,73 \mathrm{~A}$ & $46,66 \mathrm{~A}$ \\
50 & $39,93 \mathrm{~B}$ & $41,84 \mathrm{~A}$ & $57,37 \mathrm{~A}$ & $53,62 \mathrm{~A}$ \\
75 & $47,77 \mathrm{~A}$ & $43,24 \mathrm{~A}$ & $52,96 \mathrm{~A}$ & $52,21 \mathrm{~A}$ \\
100 & $44,56 \mathrm{AB}$ & $43,43 \mathrm{~A}$ & $50,31 \mathrm{~A}$ & $52,66 \mathrm{~A}$ \\
\hline $\mathrm{CV}(\%)$ & 12,00 & 20,85 & 25,74 & 36,10 \\
\hline
\end{tabular}

As médias seguidas pela mesma letra dentro da mesma coluna não diferem estatisticamente entre si pelo Teste de Tukey ao nível de $5 \%$ de probabilidade $(\mathrm{p}<0,05)$. C.V. = coeficiente de variação.

Vários estudos têm demonstrado que a aplicação de $\mathrm{Si}$ tem resultado no incremento dos teores de clorofila a e b, com os autores justificando esse efeito como sendo resultado do aumento da atividade fotossintética. Emrich et al. (2011) avaliando a produtividade do tomateiro em composto orgânico sob aplicação foliar de silicato de potássio, relatou incremento nos teores de clorofila a e b, conforme se aumentavam as dosagens. Rodrigues et al. (2016), avaliando o comportamento das clorofilas a e b em tomateiro tratado com silicato de potássio via foliar, aplicado semanalmente verificaram aumento nos teores de clorofila a, incrementando a produtividade e o número total de frutos. Em mamona submetida a estresse salino e adubação silicatada, Ferraz et al. (2015) chegaram à conclusão de que, conforme se aumentavam a concentrações de silício, maiores eram os valores obtidos para clorofila total, independentes da salinidade da água.

Para as variáveis referentes ao sistema radicular (Tabela 5) foi verificado efeito significativo, exceto para o comprimento do sistema radicular. Nas variáveis peso fresco e peso seco das raízes verificou-se que a testemunha foi superior, nas avaliações realizadas aos 45, 75 e 90 DAT. Também foi perceptível uma relação inversa entre dosagens e médias encontradas para as variáveis em questão, onde conforme se aumentava a concentração de silicato de potássio, menores valores eram encontrados. As concentrações de 50, 75, e 100 mL. $\mathrm{L}^{-1}$, apresentaram comportamento semelhante quando submetidas ao estresse.

Tabela 5 - Resumo da análise de variância e média obtidas para as variáveis comprimento da raiz (CR), peso fresco (PFR) e peso seco (PSR), Limoeiro do Norte-CE, 2017.

\begin{tabular}{|c|c|c|c|}
\hline \multirow{3}{*}{ Tratamento } & \multicolumn{2}{|c|}{ QM } & \\
\hline & CR & PFR & PSR \\
\hline & $41,92 \mathrm{~ns}$ & $83,30 * *$ & $1,36 *$ \\
\hline $\mathrm{CV}(\%)$ & 34,85 & 39,91 & 38,92 \\
\hline \multirow{2}{*}{ Doses de $\mathrm{K}_{2} \mathrm{SiO}_{3}\left(\mathrm{~mL} . \mathrm{L}^{-1}\right)$} & \multicolumn{2}{|c|}{ Médias } & \\
\hline & $20 \mathrm{DAT}$ & $75 \mathrm{DAT}$ & 90 DAT \\
\hline Testemunha & $28,12 \mathrm{~A}$ & $13,38 \mathrm{~A}$ & $2,42 \mathrm{~A}$ \\
\hline 0 & $26,86 \mathrm{~A}$ & $10,56 \mathrm{AB}$ & $1,85 \mathrm{AB}$ \\
\hline 25 & $28,89 \mathrm{~A}$ & $9,55 \mathrm{ABC}$ & $1,81 \mathrm{AB}$ \\
\hline 50 & $28,87 \mathrm{~A}$ & $4,97 \mathrm{C}$ & $1,39 \mathrm{~B}$ \\
\hline 75 & $23,57 \mathrm{~A}$ & $5,38 \mathrm{BC}$ & $1,53 \mathrm{AB}$ \\
\hline 100 & $24,14 \mathrm{~A}$ & $6,87 \mathrm{BC}$ & $1,24 \mathrm{~B}$ \\
\hline
\end{tabular}

(ns) - não significativo; $(*)$ significativo ao nível de $5 \%$ de probabilidade $(\mathrm{p}<0,05) ;(* *)$ significativo ao nível de $1 \%$ de probabilidade $(\mathrm{p}<0,01)$.

As médias seguidas pela mesma letra dentro da mesma coluna não diferem estatisticamente entre si pelo Teste de Tukey ao nível de $5 \%$ de probabilidade $(\mathrm{p}<0,05)$.

C.V. = coeficiente de variação.

Freire et al. (2010), relatam que o estresse salino acarreta mudanças no crescimento, na morfologia e na fisiologia das raízes, interferindo na absorção de água e de íons. Sendo assim, a planta toda é afetada quando cresce em meio salino. Em resultados obtidos pelos mesmos autores, não foi verificado 
efeito significativo da salinidade em relação à massa seca de raízes do tomateiro, podendo indicar que, mesmo sob condições salinas, essas são capazes de produzir um sistema radicular comparável ao das plantas do tratamento controle. Entretanto, essas informações diferem do resultado obtido no presente trabalho, em que as plantas adubadas com silício, quando submetidas ao estresse, apresentaram os maiores percentuais de matéria seca. Este comportamento pode estar relacionado com a translocação do silício da parte aérea para as raízes, parte da planta diretamente afetada pelo estresse.

Alguns autores têm proposto diversas hipóteses tentando explicar o efeito do silício sobre as plantas sob estresse salino. Porém, nenhuma constituiu uma evidência clara; dentre estas, três têm ganhado maior aceitação na comunidade científica. A primeira é que o Si diminui a concentração de sais na planta devido à diminuição da transpiração por acumulação do elemento nas folhas; a segunda é que o silício diminui o transporte de $\mathrm{Na}^{+}$nas raízes e a terceira é que o elemento tem funções fisiológicas que aumentam o metabolismo antioxidante (SHI et al., 2013).

Tuna et al. (2008) observaram que o silício aplicado a plantas de trigo submetidas a estresse salino diminuiu a permeabilidade da membrana plasmática ao sódio, mantendo-a para o potássio e cálcio, aliviando o estresse causado pelo sal. Além disso, o transporte de sódio dentro das raízes foi moderadamente reduzido pela adição de silício em condições de estresse salino. Miranda et al. (2002), ao testar o mesmo nutriente em moringa (Moringa oleifera), não verificaram efeitos benéficos sobre a produção de matéria seca de folhas, caules e raízes quando submetidas à estresse salino.

A análise de variância para as características número de flores (Tabela 6) evidenciou diferença significativa aos 27 e 87 DAT. No entanto, a redução no número de flores pode ser atribuídas às altas temperaturas observadas durante o período experimental (máxima de $40,9^{\circ} \mathrm{C}$ e mínima de 16,89 $\left.{ }^{\circ} \mathrm{C}\right)$. A temperatura média diária variou de $22,55^{\circ} \mathrm{C}$ a $36,25^{\circ} \mathrm{C}$, com média de $29,40{ }^{\circ} \mathrm{C}$ para o período de cultivo. Assim, a faixa de temperatura máxima à qual a cultura estava submetida era superior às ideais para o crescimento vegetativo e frutificação, tendo sido observado problema de queda de flores e no pegamento de frutos, e consequentemente no número total de frutos produzidos.

Tabela 6 - Resumo da análise de variância para as variáveis número de flores (NF) e número de cachos (NC) de plantas de tomate aos 27, 47, 79 e 87 dias após o transplantio (DAT), Limoeiro do Norte-CE, 2017.

\begin{tabular}{lllll}
\hline \multirow{2}{*}{ Variáveis } & \multicolumn{5}{c}{ QM } & 87 DAT \\
\cline { 2 - 5 } & $27 \mathrm{DAT}$ & $47 \mathrm{DAT}$ & $79 \mathrm{DAT}$ & $32,666^{*}$ \\
$\mathrm{NF}$ & $5,42 *$ & $30,65 \mathrm{~ns}^{*}$ & $10,90 \mathrm{~ns}$ & $2,56 \mathrm{~ns}$ \\
\hline $\mathrm{NC}$ & $0,23 \mathrm{~ns}$ & $2,43 \mathrm{~ns}$ & $1,20 \mathrm{~ns}$ & 57,65 \\
\hline
\end{tabular}

(ns) - não significativo;

(*) significativo ao nível de $5 \%$ de probabilidade $(\mathrm{p}<0,05)$;

$(* *)$ significativo ao nível de $1 \%$ de probabilidade $(\mathrm{p}<0,01)$.

Silva et al. (2013) ressaltam que a ocorrência de temperatura elevada no local de cultivo durante a época de floração influência no abortamento das flores. Segundo Alvarenga (2004), temperaturas acima de $32{ }^{\circ} \mathrm{C}$ causam abscisão floral no tomateiro. Gusmão et al. (2006) esclarecem que a queda de flores do tomateiro cultivado em ambiente com temperaturas durante o dia acima de $32^{\circ} \mathrm{C}$ é devida à inviabilidade do grão de pólen e à não fertilização dos óvulos. Em tais condições, Silva et al. (2000) ressaltam que o crescimento do tubo polínico é lento e seu desenvolvimento pode dar lugar ao envelhecimento do óvulo antes que ocorra a fecundação. Essas informações corroboram os apresentados nesta pesquisa, onde se obteve um reduzido número de flores devido à queda destas. Outros fatores como o excesso de umidade no interior de ambientes protegidos impedem a polinização das flores e provoca o abortamento e queda, quando não ocorre aplicação de hormônios vegetais. Isso acontece porque o pólen úmido se aglutina e ao cair no estigma não pode fecundar os óvulos.

De acordo com a tabela 7 , pode-se verificar que aos 27 DAT as plantas não submetidas ao estresse salino e/ou sódico (testemunha) apresentavam o melhor resultado em termos de média. No entanto, as plantas condicionadas ao fator estressante, adubadas com silicato de potássio, exceto a 75 mL.L ${ }^{-1}$ de $\mathrm{K}_{2} \mathrm{SiO}_{3}$, não divergiram da mesma. Já aos 87 DAT, as doses de silício que mais se destacaram foram as de 50,75 e $100 \mathrm{~mL} . \mathrm{L}^{-1}$, respectivamente. $\mathrm{O}$ resultado evidencia que a adubação com silício pode ter reduzido o efeito do estresse. 
Tabela 7 - Médias obtidas para variável número de flores (NF) de plantas de tomate aos 27, 47, 79 e 87 dias após o transplantio (DAT), Limoeiro do Norte-CE, 2017.

\begin{tabular}{lllll}
\hline \multirow{2}{*}{ Doses de $\mathbf{K}_{\mathbf{2}} \mathbf{S i O}_{\mathbf{3}}\left(\mathbf{m L .} \mathbf{L}^{-\mathbf{1}}\right)$} & \multicolumn{4}{c}{ Médias } \\
\cline { 2 - 5 } Testemunha & $20 \mathrm{DAT}$ & $45 \mathrm{DAT}$ & $75 \mathrm{DAT}$ & $90 \mathrm{DAT}$ \\
0 & $3,40 \mathrm{~A}$ & $12,70 \mathrm{~A}$ & $7,00 \mathrm{~A}$ & $4,62 \mathrm{~B}$ \\
25 & $2,50 \mathrm{AB}$ & $10,44 \mathrm{~A}$ & $6,56 \mathrm{~A}$ & $4,71 \mathrm{~B}$ \\
50 & $2,10 \mathrm{AB}$ & $10,22 \mathrm{~A}$ & $7,22 \mathrm{~A}$ & $6,78 \mathrm{~B}$ \\
75 & $2,80 \mathrm{AB}$ & $8,40 \mathrm{~A}$ & $6,62 \mathrm{~A}$ & $\mathrm{AB}$ \\
100 & $1,40 \mathrm{~B}$ & $8,89 \mathrm{~A}$ & $9,62 \mathrm{~A}$ \\
\hline
\end{tabular}

As médias seguidas pela mesma letra dentro da mesma coluna não diferem estatisticamente entre si pelo Teste de Tukey ao nível de $5 \%$ de probabilidade $(\mathrm{p}<0,05)$. C.V. = coeficiente de variação.

$\mathrm{Na}$ avaliação dos cachos, eram contabilizados apenas aqueles que continham flores, tendo estas sofrido grande influência ambiental, principalmente por efeito térmico, vindo a inferir nas variáveis relacionadas. As baixas médias para o número de cachos pode ser explicado por Cuartero e Muñoz (1999) ao afirmarem que os mesmos tendem a diminuir quando a água de irrigação apresenta elevada concentração de sais e sob longos períodos de exposição.

Com relação às variáveis número total de frutos (NTF) e diâmetros lateral (DLF) e vertical dos frutos (DVF), não foi observada diferença significativa entre os tratamentos (Tabela 8).

Tabela 8 - Resumo da análise de variância e média obtidas para as variáveis número total de frutos (NF), diâmetro lateral dos frutos (DLF) e diâmetro vertical dos frutos (DVF), Limoeiro do Norte-CE, 2017.

\begin{tabular}{|c|c|c|c|c|}
\hline \multirow{3}{*}{ Tratamento } & \multicolumn{3}{|c|}{ QM } & \multirow{3}{*}{$\begin{array}{l}\text { DVF (mm) } \\
66,07 \mathrm{~ns}\end{array}$} \\
\hline & NTF & PTF (g) & DLF (mm) & \\
\hline & $0,44 \mathrm{~ns}$ & $31,10 \mathrm{~ns}$ & $124,44 \mathrm{~ns}$ & \\
\hline $\mathrm{CV}(\%)$ & 91,72 & 89,36 & 75,37 & 75,18 \\
\hline \multirow{2}{*}{ Doses de $\mathrm{K}_{2} \mathrm{SiO}_{3}\left(\mathrm{~mL} \cdot \mathrm{L}^{-1}\right)$} & Médias & & & \\
\hline & $20 \mathrm{DAT}$ & 45 DAT & 75 DAT & $90 \mathrm{DAT}$ \\
\hline Testemunha & $1,12 \mathrm{~A}$ & $14,99 \mathrm{~A}$ & $23,11 \mathrm{~A}$ & $20,77 \mathrm{~A}$ \\
\hline 0 & $1,57 \mathrm{~A}$ & $13,09 \mathrm{~A}$ & $27,12 \mathrm{~A}$ & $20,58 \mathrm{~A}$ \\
\hline 25 & $1,22 \mathrm{~A}$ & $11,99 \mathrm{~A}$ & $19,81 \mathrm{~A}$ & $17,25 \mathrm{~A}$ \\
\hline 50 & $1,00 \mathrm{~A}$ & $9,42 \mathrm{~A}$ & $14,96 \mathrm{~A}$ & $13,07 \mathrm{~A}$ \\
\hline 75 & $1,00 \mathrm{~A}$ & $11,72 \mathrm{~A}$ & $20,55 \mathrm{~A}$ & $17,78 \mathrm{~A}$ \\
\hline 100 & $0,86 \mathrm{~A}$ & $10,30 \mathrm{~A}$ & $19,16 \mathrm{~A}$ & $15,82 \mathrm{~A}$ \\
\hline
\end{tabular}

(ns) - não significativo; $(*)$ significativo ao nível de 5\% de probabilidade $(\mathrm{p}<0,05) ;(* *)$ significativo ao nível de $1 \%$ de probabilidade $(\mathrm{p}<0,01)$.

As médias seguidas pela mesma letra dentro da mesma coluna não diferem estatisticamente entre si pelo Teste de Tukey ao nível de $5 \%$ de probabilidade $(\mathrm{p}<0,05)$. C.V. = coeficiente de variação.

Apesar de não estar sendo tratada com silício, as plantas do tratamento testemunha apresentaram resultados iguais estatisticamente aos demais. Entretanto, o substrato utilizado no experimento continha casca de arroz, a qual é rica em silício, podendo ter influenciado no desenvolvimento da planta, evidenciando o seu potencial na redução dos efeitos da salinidade nas plantas.

De acordo com Cuartero e Muñoz (1999) sob salinidade moderada a redução no rendimento do tomateiro deve-se, principalmente, à redução no peso médio de frutos, enquanto que em condições de alta salinidade a redução na produtividade é resultado do menor número de frutos por planta. Miyake e Takahashi (1978) constataram que plantas de tomate cultivadas em solução nutritiva com baixo teor de Si demonstraram deficiência durante a fase reprodutiva, além do mais, em solução nutritiva sem a presença de silicio o tomateiro raramente segura os frutos, ou seja, floresce, mas não produzem frutos.

\section{CONCLUSÕES}

A adubação a base de silício possibilita amenizar o efeito do estresse salino na cultura do tomate.

As variáveis altura da planta e peso fresco das raízes, apresentaram melhores resultados quando aplicada a dosagem de 25 mL.L $\mathrm{L}^{-1}$ de $\mathrm{K}_{2} \mathrm{SiO}_{3}$.Enquanto para número de folhas e de flores a concentração de $75 \mathrm{~mL} \cdot \mathrm{L}^{-1}$ favoreceu o aumento das médias.

\section{REFERÊNCIAS}

ALVAREnGA, M. A. R. Tomate: Produção em campo, em casa de vegetação e em hidroponia. Lavras: UFLA, 2004, 400p.

AYERS, R. S.; WESTCOT, D. W. A qualidade de água na agricultura. 2 ed. Campina Grande: UFPB, 1999, $153 \mathrm{p}$. 
CARVALHO JUNIOR, G. S.; ROCHA, M. S. L.; ROCHA, M. S.; MACÊDO, N. E. B.; VIDAL, K. N. Crescimento do pinhão - manso sob diferentes níveis de salinidade e silício. Revista Caatinga, Mossoró, v. 27, n. 4, p. 39-46, 2014.

CUARTERO, J.; FERNANDEZ-MUNÕZ, R. Tomato and salinity. Scientia Horticulturae, v.78, p.83-125, 1999.

EMRICH, E. B, SOUZA, R. J, LIMA, A. A, FIGUEIREDO, F. C; SILVA, D. R. G. Cultivo do tomateiro em substratos orgânicos sob aplicação foliar de silicato de potássio em ambiente protegido. Ciência e Agrotecnologia, Lavras, v. 35, n. 1, p. 56-61, 2011.

FERRAZ, R. L. S.; MAGALHÃES, I. D.; BELTRÃO, N. E. M.; MELO, A. S.; BRITO NETO, J. F.; ROCHA, M. S. Photosynthetic pigments, cell extrusion and relative leaf water contente of the castor bean under silicon and salinity. Revista Brasileira de Engenharia Agrícola e Ambiental, Campina Grande, v. 19, n. 9, p. 841-848, 2015 .

FREIRE, A. L. O.; SARAIVA, V. P.; MIRANDA, J. R. P.; BRUNO, G. B. Crescimento, acúmulo de íons e produção de tomateiro irrigado com água salina. Semina: Ciências Agrária, Londrina, v. 31, suplemento 1, p. 1133-1144, 2010.

GOMES, F. B.; MORAES, J. C.; NERI, D. K. P. Adubação com silício como fator de resistência a insetospraga e promotor de produtividade em cultura de batata inglesa em sistema orgânico. Revista Ciência e Agrotecnologia, Lavras, v. 33, n. 1, p. 18-23, 2009.

GONG, H.; ZHU, X.; CHEN, K.; WANG, S.; ZHANG, C. Silicon alleviates oxidative damage of wheat plants in pots under drought. Plant Science, v. 169, p. 313-321, 2005 .

GUEDES, R. A. A.; OLIVEIRA, F. A.; ALVES, R. C.; MEDEIROS, A. M.; GOMES, L. P.; COSTA, L. P. Estratégias de irrigação com água salina no tomateiro cereja em ambiente protegido. Revista Brasileira de Engenharia Agrícola Ambiental, Campina Grande, v. 19, n. 10, p. 913-919, 2015.

HATTORI, T.; INANAGAA, S.; ARAKI, H.; NA, P.; MORITA, S.; LUXOVA, M.; LUXE, A. Application of silicon enhanced drought tolerance in Sorghum bicolor. Physiologia Plantarum, v. 123, p. 459-466, 2005.

LIMA, M. A.; CASTRO, V. F.; VIDAL, J. B. ENEASFILHO, J. Aplicação de silício em milho e feijão-de-corda sob estresse salino. Revista Ciência Agronômica, Fortaleza, v. 42, n. 2, p. 398-403, 2011.

MA, J. F. Role of silicon in enhancing the resistance of plants to biotic and abiotic stresses. Soil Science and Plant Nutrition, v. 50, n. 1, p. 11-18, 2004.
MA, J. F.; MIYAKE, Y.; TAKAHASHI, E. Silicon as a beneficial elemento for crop plants. In: DATNOFF L.E. et al (Ed.). Silicon in Agriculture, Elsevier Science B.V., 2001.

MIRANDA, J. R. P.; CARVALHO, J. G.; SANTOS, D. R.; FREIRE, A. L. O.; BERTONI, J. C.; MELO J. R. M.; CALDAS, A. L. Silício e cloreto de sódio na nutrição mineral e produção de matéria seca de plantas de moringa (Moringa oleifera Lam.). Revista Brasileira da Ciência do Solo, Viçosa, v. 26, n. 4, p. 957-965, 2002.

MIYAKE, Y.; TAKAHASHI, E. Silicon deficiency of tomato plant. Soil Science and Plant Nutrition, v. 24, n. 2, p. 175-189, 1978.

PEREIRA JÚNIOR, P.; REZENDE, P. M.; MALFITANO, S. C.; LIMA, R. K.; CORRÊA, L. V. T.; CARVALHO, E. R. Efeito de doses de silício sobre a produtividade e características agronômicas da soja [Glycine $\max$ (L.) Merrill]. Revista Ciência e Agrotecnologia, Lavras, v. 34, n. 4, p. 908-913, 2010.

RODRIGUES, C. R.; RODRIGUES, T. M.; LUZ, J. M. Q.; SOUSA, V. B. F. DE; SOUSA, J. B.; NUNES, A. C. P.; TRINDADE, P. R. Clorofila a e b de tomateiro tratado com silicato de potássio e fungicida. Global Science and Technology, Rio Verde, v. 09, n. 2, p. 54 - 64, 2016.

SHI, Y.; WANG, Y.; FLOWERS, T. J.; GONG, H. Silicon decreases chloride transport in rice (Oryza sativa L.) in saline conditions. Journal of Plant Physiology, v.170, n.9, p. 847-853, 2013.

SILVA, A. C. T. F.; LEITE, I. C.; BRAZ, L. T. Avaliação da viabilidade do pólen como possível indicador de tolerância a altas temperaturas em genótipos de tomateiro. Revista Brasileira de Fisiologia Vegetal, Campinas, v. 12, n. 2, p. 136-165, 2000.

SILVA, J. M.; FERREIRA, R. S.; MELO, A. S.; SUASSUNA, J. F.; DUTRA, A. F.; GOMES, J. P. Cultivo do tomateiro em ambiente protegido sob diferentes taxas de reposição da evapotranspiração. Revista Brasileira de Engenharia Agrícola e Ambiental, Campina Grande, v. 17, n. 1, p. 40-46, 2013.

SORATTO, R. P.; FERNANDES, A. M.; CRUSCIOL, C. A. C.; SOUZA-SCHLICK, G. D. Produtividade, qualidade de tubérculos e incidência de doenças em batata, influenciados pela aplicação foliar de silício. Pesquisa Agropecuária Brasileira, Brasília, v. 47, n. 7, p. 1000-1006, 2012.

TREICHEL, M.; CARVALHO, C.; FILTER, C. F.; BELING, R. R. Anuário brasileiro do tomate 2016. Santa Cruz do Sul: Editora Gazeta Santa Cruz, 2016. 84 p.

TUNA, A. L.; KAYAB, C.; HIGGS, D.; AMADOR, B. M.; AYDEMIR, S.; GIRGIN, A. R. Silicon improves salinity tolerance in wheat plants. Environmental and Experimental Botany, v.62, n.1, p.10-16, 2008. 